\title{
Neck Metastatic Basal Cell Carcinoma, a Therapeutic Challenge
}

\author{
Marcos Irving Salazar Jiménez $\mathbf{M D}^{1, *}$, Javier Alvarado Durán $\mathbf{M D}^{2}$, Antonio Herrera González \\ MD $^{1}$, Cesar Alfonso Espino Rodriguez MD ${ }^{1}$, Marcela Ivette Muñoz Camacho MD ${ }^{3}$, Maria del \\ Rosario Lozada Torres MD ${ }^{1}$, Jeshua Altuve Quiroz MD $^{2}$, Daniel Flores Rodriguez MD $^{5}$, Monica \\ Elizabeth De la Torre García MD ${ }^{6}$, Luis Angel Medina Andrade MD $^{7}$, Maria Fernanda Aguilar \\ Rodriguez $\mathrm{MD}^{4}$ \\ ${ }^{I}$ General Surgery Service, Hospital Central Norte de Petroles Mexicanos, Mexico \\ ${ }^{2}$ General Surgery Service, Internal Medicine Service^, Hospital Sanatorio Durango, CDMX, Mexico \\ ${ }^{3}$ Internal Medicine Resident, Hospital Central Sur de Petroleos Mexicanos, Mexico City, Mexico \\ ${ }^{4}$ Medical Doctor, Universidad Autónoma de Guadalajara, Guadalajara Jalisco, Mexico \\ ${ }^{5}$ Plastic Surgery Service, Hospital 20 de Noviembre, ISSSTE, Mexico City, Mexico \\ ${ }^{6}$ Dermatologist, Dermato Oncologist, Dermatological Surgeon, Derma360. Mexico City, Mexico \\ ${ }^{7}$ General Surgery Service, Hospital General de Zona $1^{a}$ Dr. Rodolfo de Mucha Macias, IMSS, Mexico City, \\ Mexico
}

*Corresponding Author: Marcos Irving Salazar Jiménez MD, General Surgery Service, Hospital Central Norte de Petroles Mexicanos, Mexico.E-mail: buismedina_5@hotmail.com

\begin{abstract}
Background: The basal cell carcinoma is the most frequent malignant skin tumor. This neoplasia is related to low mortality but high morbidity secondary to the great capacity of local tissue invasion. The most important risk factor is the solar UV radiation exposure, with the white race as the most affected. In the literature, the incidence of metastasis, mainly lymph node, is reported in less than $1 \%$ of the cases.
\end{abstract}

Case Report: A male patient of 72 years-old presents to medical consult with a lesion in the inferior right eyelid. He was treated initially with resection of the lesion by plastic surgery and a local flap performed, with posterior recurrence and right extraocular muscles affection. After this, a right eye enucleation was performed, but unfortunately, local recurrence was present again with right jugular chain affection.

Discussion: The basal cell carcinoma represents the most frequent skin neoplasia, affecting the fair skin. The metastatic potential of this kind of lesions is well known although the incidence is reported as low as $1 \%$. This kind of presentation is a therapeutic challenge for the surgeon secondary to the high rate of recurrence and local destruction.

Conclusion: The basal cell carcinoma is a low frequent entity for the oncology surgeon. This case illustrates the diagnostic and therapeutic challenge for the low incidence of metastasis, and it allows us to know the experience with different therapeutic options in this cases.

Keywords: Basal cell carcinoma, skin cancer, lymph node metastasis, radical neck dissection.

\section{INTRODUCTION}

Historically the basal cell carcinoma (BCC) was described by Jacob in 1827 in Dublín, referred as a solid skin nodule surrounded by telangiectasia and commonly located in the face, with a slow evolution, capacity to ulcerate but without metastasis. The risk factors associated with their presence were the prolonged sun and wind exposition ${ }^{1}$. Actually, it is considered the most common skin neoplasia, representing the
70 to $80 \%$ of skin tumors. In the past decades, it has been observed an increasing incidence of this kind of tumors, constituting a health problem actually ${ }^{2}$.

The BCC is commonly founded with some other benign skin lesions surrounding it secondary to the prolonged sun exposition, like the actinic facial keratosis, actinic cheilitis, solar lentigo, facial telangiectasia and Racouchot-Favre syndrome. $^{3}$ 
The white race people are commonly affected, with the sun exposition as the main risk factor for their development ${ }^{4}$.

Although those tumors of slow growth rarely produce metastasis, with reports of $<1 \%$ of metastasis incidence, the incomplete or retarded treatment could increase significantly the morbidity secondary to their local invasion capacity that can destroy the surrounding skin and tissues, including cartilage and bone, especially nostrils, eyes, and ears 5 .

This report is about a patient with diagnosis of recurrent basal cell carcinoma with lesions in the inferior right eyelid, right malar region and external canthus on the same side, with intraorbital extension and lymph node metastasis to the neck lymph node chain in the II and III levels, requiring medical and surgical management by a multidisciplinary medical team in the Hospital Central Norte of Petróleos Mexicanos.

\section{CASE REPORT}

A male patient of 72 years-old, from Veracruz, come to medical consult, with a pathological background of arterial hypertension, prostatic benign hyperplasia, and without another relevant history. He referred that since April 2016 noted an exophytic lesion in the right inferior eyelid that did not disappear after four months. Initially diagnosed as stye by a general physician he received antibiotic treatment with a quinolone for 2 weeks without improving, the reason why he was referred to the plastic surgery service was basal cell carcinoma suspicious.

Is evaluated for the plastic surgery service and they described a $20 \mathrm{~mm}$ lesion with irregular borders in the right inferior eyelid. In September 2016 a resection of this lesion is performed and a reconstruction with a transposition flap plus external canthoplasty and placement of ipsilateral ear shell cartilage graft completed, superior blepharoplasty, reporting as postsurgical findings an exophytic lesion, ulcerated, of $2.0 \times 0.6 \mathrm{~cm}$, corresponding to a basal cell carcinoma with free tumor margins in the trans surgical exam.

The patient presented initially an uneventful evolution during follow up, with posterior scar induration producing inferior right ectropion, and the subsequent surgical correction, with the preoperatory facial CT scan reporting evidence of a neoplasia located in the soft tissue anterior to the right septum, affecting orbit, compromising the inferior straight eye muscle, lateral and superior straight eye muscles with extension to the posterior orbitary portion, producing a superior displacement of the eye and lateral wall bone erosion. The lesion surrounds the eye in their posterior intracoronal and extracoronal section.

According to those CT scan findings, a right orbital rash is performed by the ophthalmology service in August 2017, reporting in the histopathology exam: basal cell carcinoma with necrosis and invasion of peri orbitary tissue, without lymphovascular or perineural invasion, and without data of ocular infiltration. Surgical margins free of tumor at less than 1mm (Fig 1).

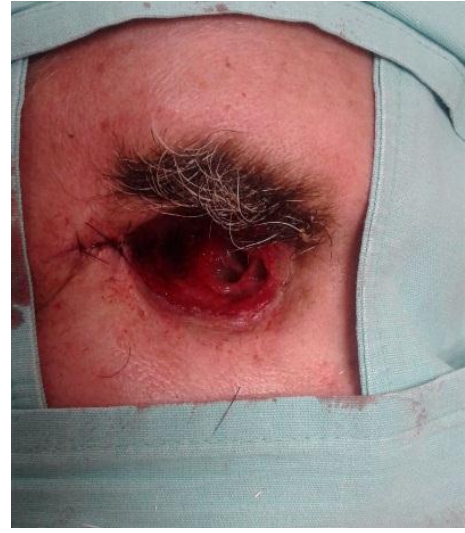

Figure 1. Patient after the right orbital rash

After two months of follow up, is referred to surgical oncology service for a right cervical lymph node, reporting a progressive increase in volume detected during auto exploration, for this reason, he looked for medical attention and a fine needle aspiration reported epithelial cells with a hemorrhagic background.

During the physical exam, a localized skin lesion in the head is observed near the right outer canthus of the eye, unilateral, asymmetric, monomorphic, a plain tumor with well-defined borders, brown coloring, with a superficial ulcer and hematic crust of $2 \mathrm{~cm} \times 5 \mathrm{~cm}$. A lymph node of $2 \mathrm{~cm}$ of diameter in the right IB neck lymph node level was detected, stony, mobile, not painful. (Figure 2)

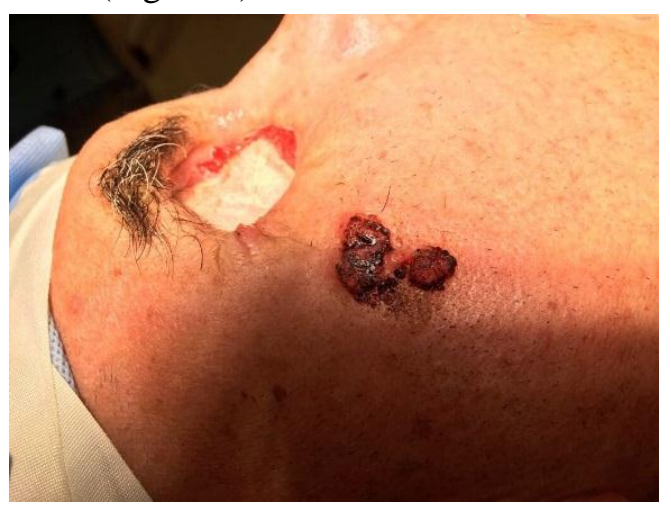

Figure 2. Right plain tumor in the right outer canthus of the eye 
In the neck CT scan, a round ganglion is reported, hypodense, of $12 \mathrm{~mm}$. of diameter localized in the right IB neck level. (Figure 3)

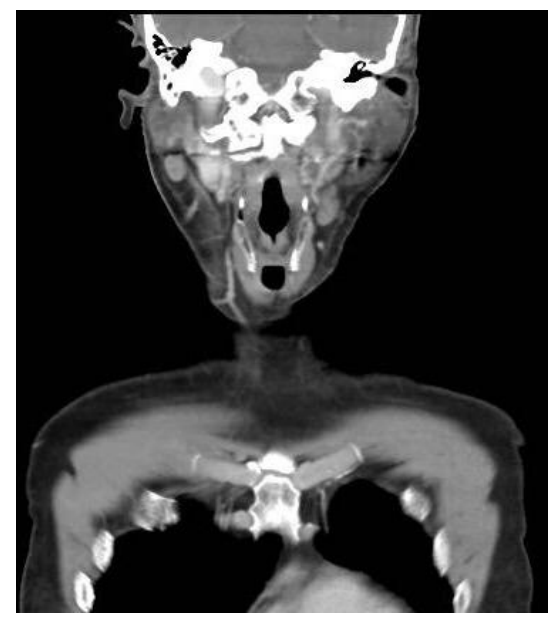

Figure 3. Neck CT contrasted scan with hypertrophic lymph nodes in the right IB neck level.

According to the findings at the physical exam, on October 10, 2017, a modified type III radical neck dissection plus primary tumors resection in the malar region and right outer canthus was performed, with trans surgical pathology exam reporting borders free of tumor.(Figure $4 a \& 4 b$ )

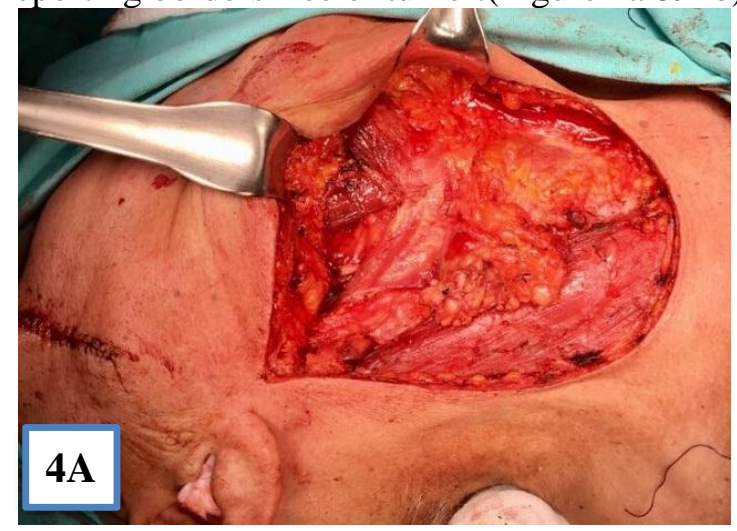

Figure 4(A). Lymph node group around the right jugular vein.

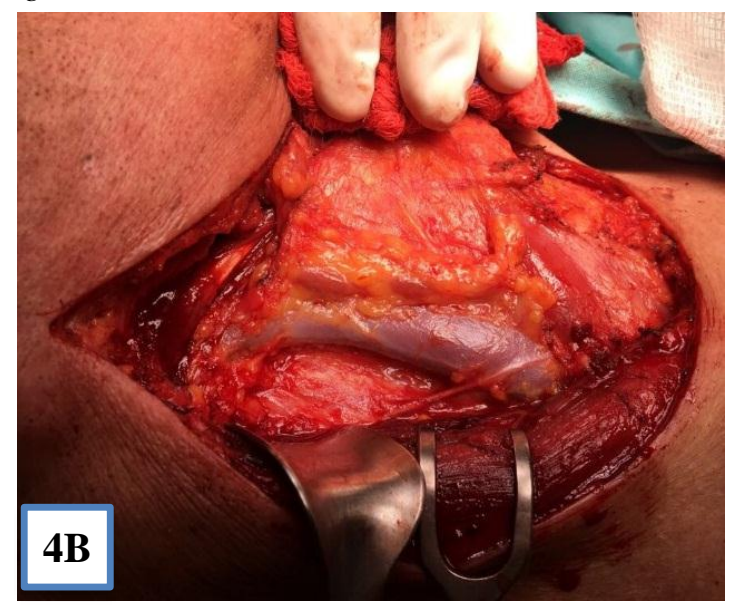

Figure 4(B). Modified radical neck dissection type III.
Definitive histopathologic report concordant with basal cell carcinoma and metastasis to 3 of 9 ganglia collected in the right radical modified neck dissection type III. (Figure 5)

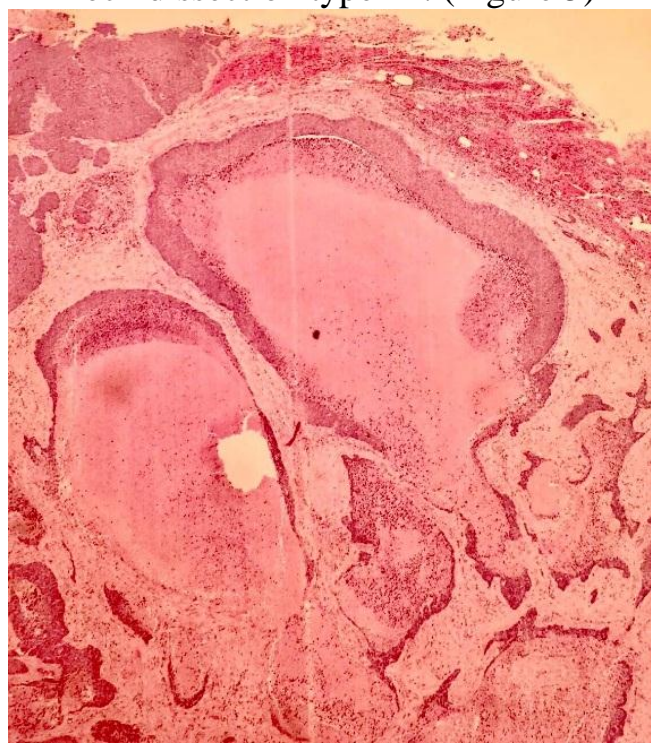

Figure 5. A 4x Hematoxylin and eosin stain of lymph node with tumoral cells.

\section{DISCUSSION}

The skin cancer represents one of the most frequent neoplasias in Mexico. The male gender is the most affected in a relation 1.5-2:1 compared with females, associated with a high rate of tumoral lesions, probably secondary to work-related risk factors, with a median age of presentation of 50 and 80 years, increasing the incidence with age, although actually, an increase in the diagnosis in people of about 40 years have been registered, representing a $5 \%$ increase in the incidence according to international publications ${ }^{2,6}$.

The main risk factors include the phototypes I and II of Fitzpatrick, familiar history of BCC (30-60\%), the presence of freckles during infancy, clear hair and eyes, increasing the risk in 10 to 20 times compared with patients of a darker skin of the same region ${ }^{1,7}$.

The work related exposition to UV radiation (farmers, fishers, masons, athletes,) and the UVB radiation or phototherapy represents the principal environment risk factos $3,4,8$.

A relation between $\mathrm{BCC}$ and seric increase of vitamin $\mathrm{D}$ had been identified, without a direct oncogenic effect, related with a chronic solar exposition without protection'. The consumption of high doses of caffeine (more than 6 cups per day) had been correlated with a decrease of $30 \%$ in the prevalence of no melanoma skin cancer in Caucasian women, 
showing a photo protection effect and diminishing the UV induced carcinogenesis ${ }^{10,11}$.

There exist 5 histological types of BCC, with the nodular and ulcerative as the most frequent, affecting the head and neck in $80 \%$ of the cases, with photo-exposed areas being the more affected (30\% in nasal area); clinically is characterized by a papule or pearl-like nodule, accompanied by telangiectasias, with secondary ulceration and deep tissue invasion ${ }^{12,13}$.

At a genetic level, there has been described some mutations in the PTCH1 gene, a tumoral suppression gen localized in the 9q22 chromosome and PTH2 localized in the $1 \mathrm{p} 32$ chromosome, both founded in the 30 to $75 \%$ of BCC cases. Similarly, the mutations in P53 gen are present in $50 \%$ of the cases, but the presence of this mutations is correlated with the progression grade, not with the ethiology $y^{3,14,15}$.

The BCC treatment is always focused in a curative resection, with the complete surgical resection as the gold standard in this kind of cancer, and the radiotherapy as an adjuvant is indicated in cases with evidence of locally advanced disease or metástasis ${ }^{16,17}$.

There exist many different accepted surgical procedures, especially for areas of aesthetic importance as the face, with the Mohs surgery or microscopy control as the first option every time is available ${ }^{17}$.

The BCC usually has a benign behavior, with a slow growth (more than 6 months to grow $1 \mathrm{~cm}$ ). The percentage of patients with surgical curative treatment exceeds the $90 \%$, with a mortality $<1 \%$. Nevertheless, in a few cases the tumor affects deep structures of the anatomy, conducing to important local morbidity and more aggressive surgeries, sometimes with permanent mutilating and disfiguring procedures to treat the disease ${ }^{17}$.

The percentage of recurrence increase in cases with an initial lesion with a diameter bigger than $2 \mathrm{~cm}$ (stage 2) and this is the importance of timely diagnosis. In average patient has 37.1 months with the lesion at the moment of diagnosis ${ }^{18}$. The percentage of recurrence is related to the presence of neoplastic cells in the surgical margins, reaching $15-67 \%$ in cases of positivity, and this is significantly diminished with negative margins $(1.3-4 \%)^{17}$.

The metastasis incidence in this kind of tumor is extremely rare, with reports at first time in 1894 by Beadles in a 46 years-old woman with a facial ulcer and metastasis to a submaxillary lymph node. Currently, the incidence reported is about $0.0028 \%$ to $0.55 \%$, with less than 400 cases reported in the literature ${ }^{3,19,20}$.

\section{Conclusions}

The BCC is currently the most frequent skin tumor worldwide, and although it is considered a tumor with benign behavior, the potential of local invasion confers a high local morbidity, a very important fact considering that the main location of this lesion is the face. The timely diagnosis is the key to an early curative treatment, and for this reason is very important to educate the first contact physicians to identify patients with risk factor of this pathology.

\section{REFERENCES}

[1] Abulafia J. Epiteliomas cutâneos: ensayo de classificación histogenética. An Bras Dermatol. 1963;38:14-31

[2] Chinem VP, Miot HA. Epidemiology of basal cell carcinoma. An Bras Dermatoll.2011;86 :292-305.[PubMed]

[3] Roewert-Huber J, Lange-Asschenfeldt B, Stockfleth E, Kerl H. Epidemiology and etiology of basal cell carcinoma. Br J Dermatol. 2007;157(Suppl 2):47-51

[4] Lear JT, Harvey I, de Berker D, Strange RC, Fryer AA. Basal cell carcinoma. J R Soc Med. 1998;91:585-8.

[5] Basal Cell Carcinoma: Pathogenesis, Epidemiology, Clinical Features, Diagnosis, Histopathology, and Management Departments of Dermatology and Internal Medicine, Yale School of Medicine, New Haven, Connecticut)

[6] Van Hattem S, Aarts MJ, Louwman WJ, Neumann HA, Coebergh JW, Looman CW, et al. Increase in basal cell carcinoma incidence steepest in individuals with high socioeconomic status: results of a cancer registry study in The Netherlands. Br J Dermatol. 2009;161:840-5.

[7] Leiter U, Garbe C. Epidemiology of melanoma and nonmelanoma skin cancer-the role of sunlight. Adv Exp Med Biol. 2008;624:89-103.

[8] Han J, Colditz GA, Hunter DJ. Risk factors for skin cancers: a nested case-control study within the Nurses' Health Study. Int J Epidemiol. 2006;35:1514-21.

[9] Asgari MM, Tang J, Warton ME, Chren MM, Quesenberry CP Jr, Bikle D, et al. Association of Prediagnostic Serum Vitamin D Levels with the Development of Basal Cell Carcinoma. J Invest Dermatol. 2010;130:1438-43

[10] Abel EL, Hendrix SO, McNeeley SG, Johnson KC, Rosenberg CA, Mossavar- Rahmani Y, et al. Daily coffee consumption and prevalence of nonmelanoma skin cancer in Caucasian women. Eur J Cancer Prev. 2007;16:446-52. 
[11] Maia M, Proenca NG, de Moraes JC. Risk factors for basal cell carcinoma: a case-control study. Rev Saude Publica. 1995;29:27-37.

[12] Kopke LFF, Schmidt SM. Carcinoma basocelular. An Bras Dermatol. 2002;77:24982.

[13] Hoban PR, Ramachandran S, Strange RC. Environment, phenotype, and genetics: risk factors associated with BCC of the skin. Expert Rev Anticancer Ther. 2002;2:570-9.

[14] Donovan J. Review of the hair follicle origin hypothesis for basal cell carcinoma. Dermatol Surg. 2009;35:1311-23.

[15] Madan V, Hoban P, Strange RC, Fryer AA, Lear JT. Genetics and risk factors for basal cell carcinoma. Br J Dermatol. 2006;154 Suppl 1:57
[16] Wetzig T, Maschke J, Kendler M, Simon JC. Treatment of basal cell carcinoma. J Dtsch Dermatol Ges. 2009

[17] Skelton LA. The effective treatment of basal cell carcinoma. Br J Nurs. 2009;18:346; 348-50

[18] Mantese SAO, Berbert ALCV, Gomides MDA, Rocha A. Carcinoma basocelular - Análise de 300 casos observados em Uberlândia - MG. An Bras Dermatol. 2006; 81:136-42.

[19] Wadhera A, Fazio M, Bricca G, Stanton O. Metastatic basal cell carcinoma: a case report and literature review. How accurate is our incidence data? Dermatol Online J. 2006;12: 7.

[20] Beadles, CF. Rodent Ulcer. Trans. Pathol. Soc. (Lond) 45, 176-81. 1894.

Citation: Marcos Irving Salazar Jiménez et al. Neck Metastatic Basal Cell Carcinoma, a Therapeutic Challenge. ARC Journal of Surgery.2018;4(2) :8-12. doi: dx.doi.org/ 10.20431/2455-572X. 0402002.

Copyright: (C) 2018 Authors. This is an open-access article distributed under the terms of the Creative Commons Attribution License, which permits unrestricted use, distribution, and reproduction in any medium, provided the original author and source are credited. 